\title{
Reducing maternal morbidity and mortality in the developing world: a simple, cost-effective example
}

\author{
This article was published in the following Dove Press journal: \\ International Journal of Women's Health \\ 4 February 2015 \\ Number of times this article has been viewed
}

\author{
Andrew Browning ${ }^{1,2}$ \\ Birhanu Menber ${ }^{2}$ \\ 'Maternity Africa, Arusha, Tanzania; \\ ${ }^{2}$ Vision Maternity Care, Barhirdar, \\ Ethiopia
}

Objectives: To determine the impact of volunteer obstetricians and midwife teams on obstetric services in a rural hospital in Ethiopia.

Methods: The intervention was undertaken in Mota district hospital, a rural hospital in the Amhara region of Ethiopia, which is the only hospital for 1.2 million people. Before the placement of volunteer teams it had a rudimentary basic obstetric service, no blood transfusion service, and no operative delivery. The study prospectively analyzed delivery data before, during, and after the placement of volunteer obstetrician and midwife teams. The volunteers established emergency obstetric care, and trained and supervised local staff over a 3-year period. Measurable outcomes consisted of the number of women delivering, the number of referrals of pregnant women, the number of maternal deaths, and the number of referrals of obstetric fistula patients.

Results: With the establishment of the service the number of women attending hospital for delivery increased by $40 \%$. In the hospital maternal mortality decreased from $7.1 \%$ to $<0.5 \%$, and morbidity, as measured by number of obstetric fistulae, decreased from $1.5 \%$ deliveries to $0.5 \%$ over the 3 -year intervention period. The improvements were sustained after handing the project back to the government.

Conclusion: The placement of volunteer teams was an effective method of decreasing maternal mortality and morbidity.

Keywords: emergency obstetric care, volunteers, obstetric fistula, emergency obstetric care

\section{Introduction}

Ethiopia has one of the worst maternal mortality ratios in the world, at 673 per 100,000 (range 54-810). ${ }^{1}$ Concealed within this figure is a marked urban/rural split. The 2011 Ethiopian Demographic Health Survey carried out by the Ministry of Health showed that in the capital, Addis Ababa, $82 \%$ of mothers deliver in a health facility whereas in the Amhara and Afar districts that are largely rural, the rates are $10 \%$ and $7 \%$, respectively. ${ }^{2}$

There are many problems involved in overcoming this. For example, in the Amhara region of Ethiopia with a population of over 20 million people there were 16 hospitals in 2010 and only six of these could reliably deliver emergency obstetric care. Lack of facilities combined with costs that were cheap in global terms (US\$5), but prohibitively expensive for the local population, poor roads and communications, most women cannot attend a hospital for their delivery. As a result only $10 \%$ of women in Ethiopia receive help from a skilled delivery assistant with some estimates of $96 \%$ women delivering at home in some areas of Ethiopia. ${ }^{3}$

The Ethiopian government has tried some programs to increase the human resources to deliver emergency obstetric care (EmOC) in those remaining hospitals. The current scheme is a 3-year master of surgery course available not only to medical doctors, but also to health officers. The master of surgery course not only covers emergency
Correspondence: Andrew Browning Selian Hospital, PO Box I654I Arusha, Tanzania

Tel +25576468 6579

Email andrew_browning@hotmail.com 
obstetric management, but also emergency surgery. However, it will be many years before the shortage in labor is resolved due to the number of candidates being trained versus the number required and the length of time it takes to train each candidate. In the meantime, the Amhara Regional Health Bureau of Ethiopia requested overseas help to overcome the labor shortage by placing volunteer teams of obstetricians and midwives in rural hospitals to help provide the service and also train local staff members in EmOC.

The objective of the study reported here was to assess the impact of placing volunteer medical teams within the Ethiopian government hospital system in targeted hospitals on maternal morbidity and mortality, before, during, and after the intervention.

The first target hospital was Mota hospital in central Amhara. It is a government district hospital that was opened in the year 2000 to service a population of 1.2 million people. It has 120 beds and is generally staffed by two to four general practitioners. These are fresh university graduates who have no surgical training or experience. Before the placement of volunteers there was no EmOC service and those women needing some emergency or operative intervention had the option of returning home or being referred to the regional referral hospital in the town of Barhirdar, 120 kilometers away along an unsealed road. There was one hospital ambulance that charged 400 Birr (or about US\$30) to take them to Barhirdar, or an unreliable bus service. The expense of both meant that most women in a critical condition were sent home. The population, knowing that there was very little help to be offered at Mota hospital generally did not present to hospital in labor. The hospital had many other problems: no running water, a temperamental generator to cover frequent power shortages, shortage of staff, no blood transfusion service, and a poor supply of drugs to the pharmacy.

\section{Materials and methods}

Volunteer teams of one obstetrician and one volunteer midwife were recruited from Holland, Australia, India, and America. They would stay for periods of 2-4 months, usually 3. Over the 3 years, eleven obstetricians and twelve midwives took part in the program. They were self-funded with respect to air travel, visas, living expenses, and health insurance. Accommodation was provided at the hospital, medical registration was organized with the Amhara National Regional State Health Bureau, and internal transport was provided by the program. The first volunteer team arrived at Mota in May 2010 and the last left in June 2013. A supervisory visit was made by a volunteer in January 2014 and then in May 2014.
Some volunteers returned for second and third terms. The role of the volunteers was to establish and provide an emergency obstetric service, including full operative and emergency care along with blood transfusion service. They were also to supervise and train local staff.

A retrospective analysis of monthly hospital records from January 2009 until April 2013 was done, with 2009 being the control year. Since the placement of the volunteer teams of obstetricians and midwives within Mota hospital began in May 2010, the intervention took place during only some months of the year, so this year was excluded from the comparison. Data were collected from the birth registry book and entered into a Microsoft ${ }^{\circledR}$ Excel spreadsheet at the end of each month and the raw data analyzed from Excel. Outcome measures were the number of deliveries before, during, and after the 3-year intervention period, the maternal mortality rate, and maternal morbidity rate, with the latter assessed by the number of referrals of obstetric fistula patients to a nearby specialist fistula repair centre. Also analyzed were the instrumental and operative delivery rates, number of women needing referral during labor, and perinatal mortality.

The placement of volunteers was phased out when the regional health bureau was able to staff the target hospital sufficiently to provide the service without outside assistance.

There was no ethical board at Mota hospital at the time of our study, and as this was a review of cases, permission to do the study was granted by the current medical director.

\section{Results}

There was a $40 \%$ increase in the number of women delivering within the hospital from 738 in 2009 to over 1,000 in both 2011 and 2012; there was a slight proportional decrease in the number of assisted vaginal deliveries (Table 1). There was an obvious increase in the number of deliveries by cesarean section as there was no service provided in 2009 (0.0\%) and the cesarean rate was $8.7 \%$ and $10.7 \%$ for 2011 and 2012 , respectively. There was a large decrease in the number of patients referred to the referral hospital in Barhirdar for further treatment: from 79 (9.3\%) pregnant women in 2009 to only one in 2011 and 2012. This referral was at a time when there was no anesthesia cover for a short period of time and the patient needed an operative delivery.

The most striking comparison is the number of maternal deaths. In 2009, it is estimated that there were 17 maternal deaths within the hospital itself (or $2.4 \%$ of women delivering), but there were at least 100 patients referred to Barhirdar or sent home in extremis during 2009 as there was nothing the hospital could offer the patients. Many women died en route to Barhirdar or after arrival and most women 
Table I Maternal outcomes at Mota hospital in 2009, 20II, and 2012

\begin{tabular}{|c|c|c|c|}
\hline & 2009 (before intervention) & 2011 & 2012 \\
\hline Mothers, n & 738 & 1,009 & 1,034 \\
\hline NVD, n & 486 & 719 & 734 \\
\hline INSTR, n & $173(26.0 \%)$ & $189(18.0 \%)$ & 191 (18.5\%) \\
\hline Destr Del, $n$ & 0 & II & 6 \\
\hline $\mathrm{CS}, \mathrm{n}$ & $0(0.0 \%)$ & $88(8.7 \%)$ & II I (I0.7\%) \\
\hline Transfers (A/N), n & $79(9.3 \%)$ & 0 & 1 \\
\hline Maternal deaths, $\mathrm{n}$ & $\sim 60\left(1: 14^{*}, 7.1 \%\right)$ & $5(1: 200 *)$ & $8(1: 130 *)$ \\
\hline Perinatal deaths, $\mathrm{n}$ & Not recorded & $106(10.5 \%)$ & $79(7.5 \%)$ \\
\hline Fistula patients referred to Barhirdar & II & 4 & 8 \\
\hline Hamlin Fistula Centre, n & & & \\
\hline
\end{tabular}

Notes: *Indicates the number of women per larger group of women; ie, "I:I4" indicates one in I4 women.

Abbreviations: A/N, antenatal; CS, cesarean section; Destr Del, destructive delivery; INSTR, instrumental delivery; NVD, normal vaginal delivery.

who went home died. Estimating that up to $50 \%$ of women transferred or sent home died would make approximately 60 maternal deaths that year, or one in 14 women presenting to the hospital (738 deliveries plus 100 women turned away; 60 deaths from 838 women). This figure could easily be higher and is thought to be a conservative estimate.

Compared with 2009, in 2011 and 2012 there were no women turned away from the hospital and only one transfer with 15 maternal deaths over the 2 years from 2,043 deliveries - this works out to be less than one in every 157 women who presented for delivery at Mota.

The number of perinatal deaths was not recorded in 2009, so comparison was not possible. The number of perinatal deaths was high in 2011 and 2012. Most of these were either stillbirths with the woman presenting late in labor with the fetus already deceased in utero on arrival, or other unavoidable deaths often associated with a long labor, uterine rupture, and sepsis.

The number patients with obstetric fistula referred from Mota hospital for fistula repair in a specialist unit in Barhirdar in 2009 was eleven, as per Mota hospital records (1.5\% of women delivering). From AB's experience of working as the surgeon at the Barhirdar Fistula Hospital during those years, on average, four fistula patients would present per month, a total of up to 48 women, most of whom delivered in Mota hospital - so the real figure is likely to be higher. After the intervention, over the 2 years, twelve $(0.5 \%$ of hospital deliveries) presented at Mota hospital with an obstetric fistula, none of whom had their fistula develop within the hospital, but already had the injury on arrival in labor.

The volunteer placements ceased in June 2013. The regional health bureau placed a local health officer with EmOC training in Mota hospital in January 2013 and the volunteers worked alongside the health officer before leaving. After withdrawing the full time volunteer presence and leaving the service in the hands of the local health officer, monitoring visits were made six and 11 months later. The number of deliveries was maintained at the same level as when the volunteers had left. The overall cesarean rate had doubled from $9.7 \%$ to $18.6 \%$ since the volunteers left. No maternal deaths and few stillbirths were recorded, although it was unclear if adequate records had been maintained for accurate comparison of the latter two parameters.

\section{Discussion}

There have been many different efforts to try to combat maternal morbidity and mortality in the developing world, from introducing "birth preparedness" schemes, ${ }^{4}$ to getting women to assess health facilities during labor, ${ }^{5}$ and even providing financial assistance and motivation. ${ }^{6,7}$ The ultimate aim of these interventions has been to get women to deliver within a health institution.

However, there has been some question as to whether it is worthwhile encouraging women to access health services if the quality of the health services is poor. ${ }^{8,9}$ Other groups have thus focused on brief periods of intensive training to improve this, but the impact of short-term training has been questioned. ${ }^{10,11}$ It is certainly our personal experience that short-term training, although enthusiastically taken on board, makes little impact on changing practices on the ground. It appears more longterm investment into training over years is what slowly brings change, which was the aim of the program reported here.

As expected, establishment of an EmOC service at Mota has had positive benefits for the women who are able to attend the hospital for antenatal care and delivery, most particularly in relation to maternal death, which fell from a conservatively estimated 1 in 14 in 2009 to 1 in 157 women delivering within the hospital during 2011 and 2012. Many of the maternal deaths were high-risk patients who had not attended any antenatal services and arrived at the hospital in labour, in extremis from surrounding rural areas.

It was interesting to note that a further increase in women coming to the hospital to deliver did not occur in the second year of activity in Mota - this has been taken to indicate that 
even though there are undoubtedly thousands more women in the region who could benefit from delivering in Mota, they live too far away to walk there, are too poor to afford public transport, or live too far away from a road. The women who came for delivery at Mota were probably only from the immediate surrounds and it is likely the women from more remote areas remained at home to deliver.

The benefits the volunteers brought were not only the introduction of a service and training of all staff, including cleaners, but also an improvement in infrastructure. The volunteers certainly felt ownership of the project and raised money from their home countries to fix the water well; replace water piping; purchase a new water pump to ensure a water supply to the hospital; and buy other surgical instruments, supplies, and training equipment.

The other impact was on the volunteers themselves, many of whom have returned for their second or third term of volunteering while two others have committed to 1-2 years of volunteering at other sites having had their "appetite whetted" for volunteer work. One volunteer described it as the "best medical moment" of her career.

The budget for the intervention was low; initial funds were used to upgrade hospital accommodation for the volunteers and in-country transport to get volunteers to the hospital. The project budget was also used to purchase new delivery equipment and an ultrasound unit, repair a water well, purchase a new pump for the well, and repair plumbing to ensure a water supply to the hospital. Collectively this came to US\$20,000 over 3 years. As already mentioned, the volunteers themselves raised a significant proportion of this budget.

Although this is a single example of one site in Ethiopia, the intervention had a very positive impact on maternal morbidity and mortality. The analysis was limited by rough, incomplete records being interpreted for 2009 and for the period of 2013 after the volunteers left.

Although the follow-up after the 3-year intervention is only at 11 months at this stage, we have seem a sustainable improvement in services and significant impact on maternal morbidity and mortality for very little overall financial input. The improvements have been maintained for 11 months after withdrawing the volunteer teams. We believe it has been a cheap, effective strategy to commence an EmOC service in an area that has never had one and we believe it is also sustainable, as the service, now successfully started, has been handed over to the responsible Ethiopian health bureau. Similar projects utilizing volunteers have been undertaken in four other hospitals in Ethiopia and two in Tanzania with similar success.

\section{Conclusion}

Placement of volunteer teams of obstetrician and midwife volunteers had a positive and ongoing impact on the women of the area of Mota in terms of both maternal morbidity and mortality. It was cheap, is easily replicable, and if volunteers can be found, can easily be introduced into other areas.

\section{Acknowledgment}

Dr David McFarlane, volunteer doctor at Mota hospital, assisted with data collection.

\section{Disclosure}

The authors declare no conflicts of interest in this work.

\section{References}

1. Federal Democratic Republic of Ethiopia Ministry of Health Planning and Programming Department. Health and Health Related Indicators. Addis Ababa: Federal Democratic Republic of Ethiopia Ministry of Health Planning and Programming Department; 1999. Available from: cnhde.ei.columbia.edu/files/5/6/2008-Feb-Fri-102213.pdf. Accessed November 6, 2014

2. Central Statistical Agency [Ethiopia] and ICF International. Ethiopia Demographic and Health Survey. Addis Ababa and Calverton, MD: Central Statistical Agency and ICF International; 2012. Available from: dhsprogram.com/pubs/pdf/FR255/FR255.pdf. Accessed November 6, 2014.

3. United Nations Development Programme (UNDP). Human Development Report 2004: Cultural Liberty in Today's Diverse World. New York, NY: UNDP; 2004. Available from: http://hdr.undp.org/ sites/default/files/reports/265/hdr_2004_complete.pdf. Accessed November 6, 2014

4. Soubeiga D, Gauvin L, Hatem MA, Johri M. Birth Preparedness and Complication Readiness (BPCR) interventions to reduce maternal and neonatal mortality in developing countries: systematic review and metaanalysis. BMC Pregnancy Childbirth. 2014;14(1):129.

5. Bhandari GP, Subedi N, Thapa J, Choulagai B, Maskey MK, Onta SR. A cluster randomized implementation trial to measure the effectiveness of an intervention package aiming to increase the utilization of skilled birth attendants by women for childbirth: study protocol. $B M C$ Pregnancy Childbirth. 2014;14:109.

6. Mbizvo MT, Say L. Global progress and potentially effective policy responses to reduce maternal mortality. Int J Gynaecol Obstet. 2012;119 Suppl 1:S9-S12.

7. Nguyen HT, Hatt L, Islam M, et al. Encouraging maternal health service utilization: an evaluation of the Bangladesh voucher program. Soc Sci Med. 2012;74(7):989-996.

8. Rai SK, Anand K, Misra P, Kant S, Upadhyay RP. Public health approach to address maternal mortality. Indian J Public Health. 2012;56(3):196-203.

9. Richard F, Witter S, de Brouwere V. Innovative approaches to reducing financial barriers to obstetric care in low-income countries. Am J Public Health. 2010;100(10):1845-1852.

10. Grady K, Ameh C, Adegoke A, et al. Improving essential obstetric and newborn care in resource-poor countries. J Obstet Gynaecol. 2011;31(1):18-23.

11. van Lonkhuijzen L, Dijkman A, van Roosmalen J, Zeeman G, Scherpbier A. A systematic review of the effectiveness of training in emergency obstetric care in low-resource environments. BJOG. 2010;117(7): 777-787. 
International Journal of Women's Health

Dovepress

\section{Publish your work in this journal}

The International Journal of Women's Health is an international, peerreviewed open-access journal publishing original research, reports, editorials, reviews and commentaries on all aspects of women's healthcare including gynecology, obstetrics, and breast cancer. The manuscript management system is completely online and includes

Submit your manuscript here: http://www.dovepress.com/international-journal-of-womens-health-journa a very quick and fair peer-review system, which is all easy to use. Visit http://www.dovepress.com/testimonials.php to read real quotes from published authors. 